\title{
DISSIMILARIDADE GENÉTICA ENTRE GENÓTIPOS DE TRIGO AVALIADOS EM CULTIVO HIDROPÔNICO SOB ESTRESSE POR ALUMÍNIO ${ }^{(1)}$
}

\author{
IVANDRO BERTAN ${ }^{(2)}$; FERNANDO IRAJÁ FELIX DE CARVALHO ${ }^{(3)}$; ANTÔNIO COSTA \\ DE OLIVEIRA ${ }^{(2)}$; JOSÉ A. G. DA SILVA ${ }^{(2)}$; GIOVANI BENIN ${ }^{(2)}$; EDUARDO ALANO VIEIRA ${ }^{(4)}$; \\ GIOVANIO. DA SILVA ${ }^{(2)}$; IRINEU HARTWIG ${ }^{(2)}$; IGOR PIREZ VALÉRIO ${ }^{(5)}$; TACIANE FINATTO ${ }^{(5)}$
}

\begin{abstract}
RESUMO
O conhecimento da distância genética entre genótipos é importante ferramenta utilizada na escolha de genitores que vão dar origem às populações segregantes. Essa informação serve como parâmetro para indicação de cruzamentos que possibilitem recuperar recombinantes superiores para o caráter desejado. O principal objetivo do estudo foi promover informações de dissimilaridade genética para o caráter tolerância ao alumínio tóxico em genótipos de trigo da Região Sul do Brasil, avaliados em cultivo hidropônico sob estresse por alumínio em nível tóxico, utilizando diferentes técnicas de agrupamento e visualização gráfica. Entre os 23 genótipos testados, foi constatada a presença de variabilidade genética para tolerância ao alumínio, verificada pela formação de diferentes classes na média das variáveis consideradas bem como agrupamentos distintos. As técnicas de agrupamento e dispersão gráfica utilizadas juntamente com a comparação de médias permitiram identificar de modo eficiente os genótipos promissores na formação de populações segregantes superiores para o caráter estudado. Os genótipos ICAT 01338, ICAT 011, ICA 2, ICA 5, CD 106, CEP 24, CD 103, CD 105, IPR 85, IPR 110 e ICAT 012 são indicados para cruzamentos na expectativa de incremento de tolerância ao alumínio nas progênies formadas.
\end{abstract}

Palavras-chave: seleção de genitor, alumínio tóxico, Triticum aestivum L.

\section{ABSTRACT \\ GENETIC DISSIMILARITY AMONG WHEAT GENOTYPES EVALUATED IN HYDROPONIC CULTURE UNDER ALUMINUM STRESS}

The quantification of genetic distance among genotypes is an important tool for the choice of parents originating the segregating populations. This information serves as a parameter for directing crosses that increase the probability of recover superior recombinants for the desired character. The main object of this study was to provide information recording the genetic dissimilarity for the character tolerance to toxic aluminum in wheat genotypes from the Southern Region of Brazil, evaluated in hydroponic culture under aluminum stress, using different clustering and graphic techniques. It was observed the presence of genetic variability of tolerance to aluminum, among the 23 tested genotypes, due to the formation of different classes of variable means as well as distinct clusters. The clustering and graphic techniques used plus the comparison of means, allowed to efficiently identify promising genotypes for composing superior segregant populations for the studied character. The genotypes ICAT 01338, ICAT 011, ICA 2, ICA 5, CD 106, CEP 24, CD 103, CD 105, IPR 85, IPR 110 e ICAT 012 are indicated for crosses aiming at to increase aluminum tolerance in the progenies.

Key words: parental selection, Aluminum toxicity, Triticum aestivum L.

$\left({ }^{1}\right)$ Recebido para publicação em 14 de outubro de 2004 e aceito em 23 de janeiro de 2006.

$\left({ }^{2}\right)$ Pós-Graduados em Agronomia (Fitomelhoramento), Mestrado, Faculdade de Agronomia Eliseu Maciel/Universidade Federal de Pelotas (FAEM/UFPel). E-mail: ivandrobertan@yahoo.com.br

(3) Faculdade de Agronomia Eliseu Maciel, FAEM/UFPel, Caixa Postal 354, 96001-970 Capão do Leão (RS).

$\left({ }^{4}\right)$ Embrapa Cerrados. Caixa Postal 8223, 73310-970 Planaltina (DF)

$\left({ }^{5}\right)$ Estagiários no Departamento de Fitomelhoramento, FAEM/UFPel. 


\section{INTRODUÇÃO}

A escolha de genitores para formação de populações segregantes é uma das principais decisões que melhoristas de trigo precisam tomar. A quantificação da dissimilaridade genética pode servir como parâmetro para identificação de genitores que possibilitem maior efeito heterótico na progênie e maior possibilidade de recuperação de recombinantes superiores nas gerações segregantes. Para Moura et al. (1999), a determinação da dissimilaridade genética, por meio da avaliação simultânea de vários caracteres, pode ser uma ferramenta eficiente para a identificação de genótipos superiores, possibilitando a concentração de esforços nas combinações mais promissoras.

Por meio da estimativa da distância genética, é possível selecionar genitores para a formação de populações de melhoramento. Uma população originada do cruzamento entre indivíduos superiores e geneticamente dissimilares, terá grande probabilidade de originar populações com ampla variabilidade genética e com maior possibilidade de seleção de transgressivos para o caráter de interesse. Tal expectativa decorre do fato de que a heterose e a capacidade específica de combinação entre dois genitores dependem da existência de dominância no controle do caráter e da presença de dissimilaridade (FALCONER e MACKAY, 1996). Desse modo, é possível que genótipos geneticamente dissimilares, porém com fenótipos similares e superiores para o caráter de interesse, tenham locos distintos controlando o caráter, que podem vir a ser reunidos em um terceiro genótipo, dando origem a um segregante transgressivo para o caráter sobre seleção, pela ação de genes complementares (CARVALHO et al., 2001).

O efeito tóxico do alumínio pode manifestarse pela limitação do crescimento radicular, bem como a interferência na absorção, transporte e utilização de nutrientes (SILVA et al., 1984). Sintomas de amarelecimento e de redução de crescimento de planta foram identificados pela primeira vez em trigo e outros cereais de estação fria por BECKMANN (1954) recebendo a denominação de "crestamento"; os trabalhos de melhoramento visando tolerância ao alumínio são descritos internacionalmente a partir de 1925.

A avaliação em campo da reação ao alumínio tóxico é a mais utilizada pelos melhoristas, por possibilitar a adaptação ao ambiente e a seleção múltipla para caracteres agronômicos de interesse. Entretanto, nesse método de avaliação pode haver o inconveniente de reunir grande número de variáveis não controláveis (FURLANI e CLARK, 1981), que podem interferir negativamente na precisão experimental. Assim, o emprego de solução nutritiva e $\mathrm{Al}^{3+}$ em cultivo hidropônico, permite imediata observação dos efeitos pela inibição do crescimento da raiz, evitando os inconvenientes do uso de solo onde a intensidade de seleção não pode ser quantitativamente controlada. Muitos trabalhos foram realizados e sugerem que mediante medidas da retomada do crescimento das raízes após o tratamento com alumínio em solução nutritiva, é possível discriminar genótipos de trigo tolerantes em relação aos genótipos sensíveis ao alumínio tóxico (CAMArgo e Oliveira, 1981; Aniol, 1990; Minella e Sorrels, 1992; Camargo et al., 1992; Riede e Anderson, 1996). A dose de 10 ppm foi reportada por CAMARGo e OliveIRa (1981) e DoRnElles et. al. (1997) como o ponto determinante para alcançar níveis tóxicos do alumínio às plantas de trigo.

Considerando a importância que a tolerância ao alumínio tóxico representa para o melhoramento genético do trigo, fica evidente a necessidade do desenvolvimento de genótipos superiores para o caráter, o que justifica o direcionamento de esforços na caracterização do germoplasma existente. Dessa forma, os objetivos do presente trabalho foram: a) estimar a dissimilaridade genética entre cultivares de trigos da Região Sul do Brasil por meio de variáveis aferidas em cultivo hidropônico sob estresse por alumínio tóxico mais a variável estatura de planta a campo; b) estimar a contribuição relativa das variáveis para a dissimilaridade genética; c) comparar diferentes métodos de visualização gráfica das distâncias e d) apontar combinações híbridas promissoras para a obtenção de populações segregantes com elevado nível de tolerância ao alumínio tóxico.

\section{MATERIAL E MÉTODOS}

O experimento foi desenvolvido no laboratório de Di-haplóides e Hidroponia do Centro de Genômica e Fitomelhoramento da Faculdade de Agronomia Eliseu Maciel, da Universidade Federal de Pelotas (FAEM/UFPel), em Capão do Leão (RS). As 23 cultivares de trigo utilizadas no presente trabalho, a instituição e local em que foram desenvolvidos, constam na tabela 1 . A cultivar CEP 24 foi utilizada como padrão de tolerância e a Sonora 64 como padrão de sensibilidade ao $\mathrm{Al}^{3+}$ (SILva et al., 2004).

Para avaliação da tolerância ao estresse ao alumínio tóxico foi empregado o cultivo hidropônico. As sementes, depois de desinfetadas em solução de hipoclorito de sódio a $20 \%$ (do produto comercial) por aproximadamente 15 minutos, foram colocadas em gerbox sobre papel de germinação umedecido e levadas para câmara de crescimento na temperatura de $25^{\circ} \mathrm{C}$, por dois dias, para reiniciar o processo de 
germinação. Foram empregadas dez sementes de cada genótipo por repetição, no total de três repetições, e cada um dos genótipos com raiz de aproximadamente $2 \mathrm{~mm}$ foram alocados em fileiras, sobre uma tela de plástico adaptada à tampa de um recipiente de 5,5 litros de capacidade, empregando solução nutritiva completa, conforme CAMARgo e Oliveira (1981) e DORNELles (1994), por um período de 48 horas.

Os recipientes foram alocados em um tanque de metal tipo banho-maria a uma temperatura de 25 $\pm 1{ }^{\circ} \mathrm{C}$, com iluminação artificial e aeração constante. Após 48 horas em solução nutritiva completa, as tampas com os genótipos foram trocadas para os baldes com a solução tratamento, contendo $10 \%$ da concentração de nutrientes utilizados na solução nutritiva completa, com exceção de fósforo, que foi omitido a fim de evitar a precipitação do $\mathrm{Al}^{3+}$. $\mathrm{O}$ pH foi ajustado para quatro e o tratamento com alumínio tóxico foi aplicado na concentração de 10 ppm, tendo as plântulas permanecido por um período de 48 horas em contato com a solução tratamento. Passado esse período, os genótipos foram submetidos novamente à solução nutritiva completa por mais 72 horas, para propiciar o recrescimento das raízes.

No fim desse procedimento, as plântulas foram retiradas do sistema hidropônico e conduzidas para a avaliação fenotípica, na qual foram aferidos os seguintes caracteres: retomada do crescimento da raiz em mm (RCR), número de raízes (NR), comprimento total das raízes, em $\mathrm{cm}(\mathrm{CR})$, comprimento do coleóptilo,

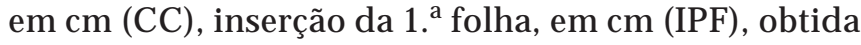
da base do colmo até a altura do encontro de inserção da $1 .^{\text {a }}$ folha; comprimento da $1 .^{\text {a }}$ folha, em cm (CPF), comprimento da 2. ${ }^{a}$ folha, em $\mathrm{cm}$ (CSF) e estatura de plântula, em cm (EPH) quantificada desde a base da plântula até seu ápice. As informações do caráter estatura de planta em campo foram obtidas mediante informações dos melhoristas responsáveis e/ou junto às entidades de pesquisa que deram origem a cada genótipo em estudo.

Tabela 1. Genótipos de trigo avaliados com as respectivas instituições de origem, FAEM/UFPEL, 2004

\begin{tabular}{|c|c|}
\hline Genótipo & Instituição*/localização \\
\hline CD 103 & COODETEC / Cascavel - PR \\
\hline CD 104 & COODETEC / Cascavel - PR \\
\hline CD 105 & COODETEC / Cascavel - PR \\
\hline CD 106 & COODETEC / Cascavel - PR \\
\hline CD 107 & COODETEC / Cascavel - PR \\
\hline CD 108 & COODETEC / Cascavel - PR \\
\hline CD 109 & COODETEC / Cascavel - PR \\
\hline CD 110 & COODETEC / Cascavel - PR \\
\hline CD 111 & COODETEC / Cascavel - PR \\
\hline BRS 177 & EMBRAPA Trigo / Passo Fundo - RS \\
\hline BRS 208 & EMBRAPA Trigo / Passo Fundo - RS \\
\hline BRS 220 & EMBRAPA Trigo / Passo Fundo - RS \\
\hline SONORA 64 & EMBRAPA Trigo / Passo Fundo - RS \\
\hline CEP 24 & EMBRAPA Trigo / Passo Fundo - RS \\
\hline IPR 85 & IAPAR / Londrina - PR \\
\hline IPR 87 & IAPAR / Londrina - PR \\
\hline IPR 110 & IAPAR / Londrina - PR \\
\hline BIESEK & ICA Melhoramento Genético Ltda / Pato Branco - PR \\
\hline ICAT 012 & ICA Melhoramento Genético Ltda / Pato Branco - PR \\
\hline ICAT 01338 & ICA Melhoramento Genético Ltda / Pato Branco - PR \\
\hline ICAT 011 & ICA Melhoramento Genético Ltda / Pato Branco - PR \\
\hline ICA 2 & ICA Melhoramento Genético Ltda / Pato Branco - PR \\
\hline ICA 5 & ICA Melhoramento Genético Ltda / Pato Branco - PR \\
\hline
\end{tabular}

* COODETEC - Cooperativa Central Agropecuária de Desenvolvimento Tecnológico e Econômico Ltda EMBRAPA - Empresa Brasileira de Pesquisa Agropecuária.

IAPAR - Instituto Agronômico do Paraná. 
Os dados foram submetidos à análise de variância univariada e comparação de médias pelo teste de Scott e Knott (SсотT e KNOTT, 1974), ao valor nominal de $1 \%$ de probabilidade. A distância genética entre todos os pares de genótipos foi estimada por meio da distância generalizada de Mahalanobis $\left(\mathrm{D}^{2}\right)$ a partir de médias padronizadas, utilizando o programa computacional GENES (CRUZ, 2001). Com base na matriz de dissimilaridade genética gerada foi aplicado o método de agrupamento de Tocher (RAO, 1952) e construído um dendrograma pelo método de agrupamento da distância média (UPGMA).

Para a estimativa do ajuste entre a matriz de dissimilaridade e o dendrograma gerado foi calculado o coeficiente de correlação cofenética (r) (SoKal e RoHLF, 1962), utilizando o programa computacional NTSYS pc 2.1 (RoHLF, 2000). A importância relativa dos caracteres avaliados para a estimativa da dissimilaridade genética foi obtida por meio da participação dos componentes da $\mathrm{D}^{2}$, relativos a cada caráter, no total da dissimilaridade observada (SINGH, 1981). Foi efetuada também a análise de variáveis canônicas (a partir de médias padronizadas) através do programa computacional GENES (CRUZ, 2001), a fim de obter a dispersão gráfica em espaço bidimensional dos genótipos estudados.

\section{RESULTADOS E DISCUSSÃO}

A análise de variância revelou diferenças significativas $(P<0,01)$ para todas as variáveis analisadas, o que evidencia a presença de variabilidade genética entre as cultivares, exceto para o número de raízes (NR) e comprimento do coleóptilo (CC), que não evidenciaram diferenças significativas, o que pode ser observado pela reduzida amplitude de médias de 4,0 a $6,0 \mathrm{~cm}$ para o NR e de 2,2 a $3,8 \mathrm{~cm}$ para CC (Tabelas 2 e 3). Entretanto, as demais variáveis apresentaram elevada amplitude de médias, como pode ser verificado para a retomada do crescimento de raiz (RCR) que variou de 1 a $41 \mathrm{~mm}$ de comprimento. Além disso, os baixos coeficientes de variação, em todas as variáveis estudadas, é indicativo de elevada precisão do experimento (Tabela 2).

As diferenças entre os genótipos destacaram a presença de variabilidade genética, principalmente, para as variáveis RCR e EPH que evidenciaram oito e seis classes distintas, respectivamente, conforme diferenciação sugerida pela aplicação do teste de Scott e Knott (Tabela 3). As variáveis CR, IPF, CPF e CSF evidenciaram limitado número de classes. Desta forma, fica evidente a grande importância da variável RCR na caracterização dos genótipos de trigo avaliados. Tal variável tem a propriedade de quantificar efetivamente a tolerância ou sensibilidade ao $\mathrm{Al}^{3+}$, como reportado por BENIN et al. (2004). Esses autores avaliaram genótipos de aveia e verificaram valores de retomada do crescimento de raiz que permitiram perfeita discriminação entre os genótipos sensíveis e tolerantes. As variáveis avaliadas na parte aérea das plântulas, bem como a estatura de planta em campo, não foram eficientes na discriminação dos genótipos avaliados em cultivo hidropônico sob estresse por $\mathrm{Al}^{3+}$. Possivelmente, estejam mais relacionadas aos fatores intrínsecos da genética da planta para crescimento da parte aérea do que com a interferência do alumínio.

Tabela 2. Resumo da análise de variância univariada contendo fontes de variação, número de graus de liberdade, quadrados médios, e valores mínimo e máximo e coeficiente de variação $(\mathrm{CV})$, para caracteres indicativos de tolerância ao alumínio tóxico na concentração de 10 ppm de $\mathrm{AL}^{3+}$, FAEM/UFPEL, 2004

\begin{tabular}{lcccccccccc}
\hline \multirow{2}{*}{ FV } & GL & \multicolumn{10}{c}{ Caracteres } \\
\cline { 3 - 10 } & & RCR & CR & NR & EPC & EPH & CC & IPF & CPF & CSF \\
\hline Blocos & 2 & 0,74 & 0,01 & 0,01 & 39,59 & 0,02 & 0,03 & 0,07 & 0,25 & 1,7 \\
Genótipos & 22 & $539^{*}$ & $5,11^{*}$ & 0,84 & $443,56^{*}$ & $17,96^{*}$ & 0,27 & $3,51^{*}$ & $7,20^{*}$ & $7,72^{*}$ \\
Erro & 44 & 4,36 & 0,47 & 0,15 & 10,22 & 0,51 & 0,02 & 0,17 & 0,35 & 0,5 \\
Valores mínimos & & 1,0 & 4,2 & 4,0 & 62,0 & 14,3 & 2,2 & 3,1 & 10,7 & 6,3 \\
Valores máximos & & 41,0 & 10,7 & 6,0 & 125,0 & 25,8 & 3,8 & 8,6 & 18,0 & 15,5 \\
\hline CV & & 15,7 & 10,2 & 7,9 & 3,8 & 3,8 & 5,1 & 7,9 & 4,4 & 7,7 \\
\hline
\end{tabular}

* Significativo a $1 \%$ de probabilidade, pelo teste F. RCR: retomada do crescimento da raiz. CR: comprimento de raízes. NR: número de raízes por plântula. EPC: estatura de planta em campo. EPH: estatura de plântula hidropônica. CC: comprimento do coleóptilo. IPF: inserção da primeira folha. CPF: comprimento da $1 .^{a}$ folha. CSF: Comprimento da $2 .^{a}$ folha. 
Nas linhagens ICAT 01338 e ICAT 011, observaram-se os maiores valores de RCR, com 37,3 e $36,5 \mathrm{~mm}$, respectivamente, indicando serem as mais tolerantes, superando o valor médio apresentado pela testemunha tolerante (CEP 24). Nas cultivares ICA 2 $(32,7 \mathrm{~mm})$, ICA $5(32,0 \mathrm{~mm})$, CD $106(28,3 \mathrm{~mm})$ e o BRS $220(27,3 \mathrm{~mm})$ também se verificaram valores elevados de RCR e podem ser enquadradas como boas fontes de tolerância ao alumínio tóxico. Valores inferiores, porém expressivos, foram verificados para os genótipos CD 103 (20,0 mm), ICAT 012 (17,7 mm), IPR 85 (15,3 mm), CD $105(15,3 \mathrm{~mm})$ e IPR $110(13,3 \mathrm{~mm})$, sendo esses classificados como de tolerância intermediária à toxicidade ao alumínio. Os demais genótipos, cujos valores de retomada do crescimento da raiz ficaram entre $1,1 \mathrm{~mm}$ e $1,9 \mathrm{~mm}$, foram classificadas como sensíveis ao $\mathrm{Al}^{3+}$.

A diferenciação das classes tolerante, intermediária e sensível, nos genótipos de trigos avaliados, cuja origem é a Região Sul do Brasil, pode estar diretamente relacionada às diferenças de características do solo. Em muitos locais do sul do país é comum a ocorrência de solos ácidos com a presença de alumínio em níveis que causam toxidez, como é o caso da Região Sudoeste do Estado do Paraná (Oliveira e PArra, 2003). Nessa região se localiza o programa de melhoramento que desenvolveu e selecionou os genótipos com maior potencial de tolerância ao alumínio tóxico, como é o caso das linhagens ICAT 01338 e ICAT 011. Esses resultados reforçam a afirmativa de ANDRADE (1976), de que a tolerância ao alumínio tóxico está intimamente ligada à origem de cada genótipo, e que dificilmente uma linhagem criada e desenvolvida sem pressão de seleção para tolerância a níveis tóxicos de alumínio terá em sua constituição genética a presença de genes para o caráter.

O método de agrupamento de Tocher possibilitou a classificação dos 23 genótipos em três grupos distintos (Tabela 3). A formação desses grupos representa valiosa informação na escolha de genitores dentro dos programas de melhoramento, pois as novas populações híbridas a serem estabelecidas devem ser embasadas na magnitude de suas dissimilaridades e no potencial "per se" dos genitores.

Pode ser verificado (Tabela 3) que o grupo II reuniu os genitores que evidenciaram elevado desempenho quanto à tolerância ao alumínio e o grupo I os genótipos sensíveis ao elemento, exceto CD 103, CD 105, IPR 85, IPR 110, e ICAT 012. O grupo III foi formado unicamente pelo genótipo padrão para tolerância CEP 24, em vista do expressivo desempenho do genótipo para a maioria dos caracteres aferidos (Tabela 3). Contudo, além de serem reunidos em grupos distintos, é necessário que os genótipos destinados a hibridações associem elevado potencial de tolerância. Assim, recomenda-se o cruzamento entre os genótipos ICAT 01338, ICAT 011, ICA 2, ICA 5, CD 106 e BRS 220 do grupo II com o genótipo CEP 24 do grupo III ou com as cultivares CD 103, ICAT 012, CD 105, IPR 85 e IPR 110 do grupo I.

Analisando a contribuição relativa dos caracteres avaliados para a dissimilaridade genética (Tabela 4), é possível identificar que a RCR foi altamente eficiente em expressar as diferenças genéticas entre os 23 genótipos de trigo avaliados, contribuindo com $61,18 \%$ da dissimilaridade total. BENIN et al. (2004) verificaram maiores valores de contribuição relativa para a dissimilaridade genética na variável RCR. O estudo da tolerância ao alumínio, em genótipos de trigo, evidenciou não existir associação entre a RCR e as demais variáveis medidas em plântulas sob cultivo hidropônico, indicando ser essa variável a única que pode ser utilizada de modo confiável na caracterização de genótipos com diferentes níveis de tolerância (SILva et al., 2004).

As demais variáveis com estimativas de contribuição relativa de pequena magnitude não são consistentes na quantificação da dissimilaridade genética. Entretanto, cabe ressaltar que as demais variáveis podem ser importantes para a quantificação da dissimilaridade genética dos genótipos, em sentido mais amplo, e não somente para a tolerância ao $\mathrm{Al}^{3+}$, principalmente quando houver interesse em identificar e reunir em uma cultivar diferentes genes de resistência.

A partir da análise visual da figura 1, é possível verificar a formação de quatro grandes grupos, sendo o primeiro grupo (I) formado pelos genótipos CD 103, CD 105, ICAT 012, BRS 220, IPR 85 e IPR 10. O grupo II foi subdividido em três subgrupos: a) formado por CD 104, CD 110, CD 107, IPR 87, CD 111, BRS 177 e Sonora 64; b) CD 108, CD 109 e Biesek e; c) pelo genótipo BRS 208. O grupo III foi formado pelos genótipos CD 106, ICAT 011, ICA 5, ICAT 01338 e ICA 2; e o IV grupo formado pelo genótipo CEP 24. Tais inferências podem ser efetuadas com segurança, uma vez que se observa no dendrograma coeficiente de correlação cofenético de 0,81 , o que indica bom ajuste entre a matriz de dissimilaridade e a representação gráfica obtida.

Os genótipos com menor dissimilaridade foram: CD 107 X IPR 87, CD 104 X CD 110 e BRS 177 X Sonora 64 (Figura 1). A maior distância em relação aos demais foi notada no genótipo CEP 24, sugerindo a possibilidade de sua utilização em cruzamentos com qualquer um dos demais genótipos. 
Tabela 3. Distribuição dos genótipos de trigo em grupos estabelecidos pelo método de Tocher, classificação segundo alumínio tóxico e comparação de médias para os caracteres indicativos de tolerância ao alumínio tóxico (teste Scott e Knott, 1974) entre os 23 genótipos de trigos do Sul do Brasil, submetidos a 10 ppm de Al ${ }^{3+}$, FAEM/UFPEL, 2004

\begin{tabular}{|c|c|c|c|c|c|c|c|c|c|c|c|}
\hline \multirow{2}{*}{ Genótipos } & \multirow{2}{*}{ Grupo } & \multirow{2}{*}{ Classificação } & \multicolumn{9}{|c|}{ Caracteres } \\
\hline & & & RCR & CR & NR & EPC & EPH & $\mathrm{CC}$ & IPF & CPF & CSF \\
\hline & & & $\mathrm{mm}$ & & 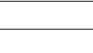 & 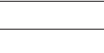 & - & 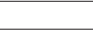 & 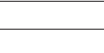 & 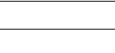 & 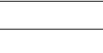 \\
\hline CD 103 & I & I & $20,0 \mathrm{~d}$ & 9,4 a & $4,3 \mathrm{a}$ & $85 \mathrm{~d}$ & $23,0 \mathrm{~b}$ & $3,0 \mathrm{a}$ & $6,2 \mathrm{~b}$ & $16,2 \mathrm{a}$ & $9,6 \mathrm{~b}$ \\
\hline CD 104 & I & S & $1,1 \mathrm{~h}$ & $5,8 \mathrm{~b}$ & $4,5 \mathrm{a}$ & $81 \mathrm{e}$ & $18,0 \mathrm{~d}$ & $2,8 \mathrm{a}$ & $5,4 \mathrm{c}$ & $12,7 \mathrm{c}$ & $10,6 \mathrm{~b}$ \\
\hline CD 105 & I & I & $15,3 \mathrm{f}$ & 8,9 a & $4,4 \mathrm{a}$ & $82 \mathrm{e}$ & 20,7 c & $2,7 \mathrm{a}$ & $5,8 \mathrm{c}$ & $15,0 \mathrm{~b}$ & $9,1 \mathrm{c}$ \\
\hline CD 107 & I & S & $1,1 \mathrm{~h}$ & $6,8 \mathrm{~b}$ & 4,4 a & $88 \mathrm{c}$ & $18,5 \mathrm{~d}$ & $2,8 \mathrm{a}$ & $5,8 \mathrm{c}$ & $13,1 \mathrm{c}$ & $7,9 \mathrm{c}$ \\
\hline CD 108 & I & S & $1,1 \mathrm{~h}$ & $5,3 \mathrm{~b}$ & $5,2 \mathrm{a}$ & $67 \mathrm{i}$ & $16,4 \mathrm{e}$ & $2,3 \mathrm{a}$ & $4,4 \mathrm{c}$ & $11,5 \mathrm{c}$ & $7,8 \mathrm{c}$ \\
\hline CD 109 & I & S & $1,9 \mathrm{~h}$ & $5,5 \mathrm{~b}$ & $4,8 \mathrm{a}$ & $72 \mathrm{~h}$ & $17,5 \mathrm{~d}$ & $2,8 \mathrm{a}$ & $5,4 \mathrm{c}$ & $12,1 \mathrm{c}$ & $8,5 \mathrm{c}$ \\
\hline CD 110 & I & S & $1,2 \mathrm{~h}$ & $5,6 \mathrm{~b}$ & $5,0 \mathrm{a}$ & 81 e & $18,8 \mathrm{~d}$ & $2,9 \mathrm{a}$ & $4,9 \mathrm{c}$ & $13,1 \mathrm{c}$ & $9,8 \mathrm{~b}$ \\
\hline CD 111 & I & S & $1,1 \mathrm{~h}$ & $6,7 \mathrm{~b}$ & $4,8 \mathrm{a}$ & 82 e & $18,0 \mathrm{~d}$ & $2,9 \mathrm{a}$ & $4,8 \mathrm{c}$ & $13,3 \mathrm{c}$ & $7,9 \mathrm{c}$ \\
\hline BRS 177 & I & S & $1,1 \mathrm{~h}$ & $6,8 \mathrm{~b}$ & $5,9 \mathrm{a}$ & $85 \mathrm{~d}$ & $17,8 \mathrm{~d}$ & $2,9 \mathrm{a}$ & $5,1 \mathrm{c}$ & $12,9 \mathrm{c}$ & $8,9 \mathrm{c}$ \\
\hline BRS 208 & I & S & $1,2 \mathrm{~h}$ & $5,6 \mathrm{~b}$ & $5,1 \mathrm{a}$ & $89 \mathrm{c}$ & $22,5 \mathrm{~b}$ & $3,1 \mathrm{a}$ & 7,5 a & $15,2 \mathrm{~b}$ & $10,5 \mathrm{~b}$ \\
\hline IPR 85 & I & I & $15,3 \mathrm{f}$ & $5,8 \mathrm{~b}$ & $5,8 \mathrm{a}$ & $85 \mathrm{~d}$ & $17,4 \mathrm{~d}$ & $2,7 \mathrm{a}$ & $5,1 \mathrm{c}$ & $12,4 \mathrm{c}$ & $9,4 \mathrm{~b}$ \\
\hline IPR 87 & I & S & $1,1 \mathrm{~h}$ & $6,8 \mathrm{~b}$ & $4,9 \mathrm{a}$ & $89 \mathrm{c}$ & $19,3 \mathrm{~d}$ & $2,7 \mathrm{a}$ & $6,2 \mathrm{~b}$ & $13,3 \mathrm{c}$ & $9,4 \mathrm{~b}$ \\
\hline IPR 110 & I & I & $13,3 \mathrm{~g}$ & $5,8 \mathrm{~b}$ & $5,7 \mathrm{a}$ & $74 \mathrm{~g}$ & $19,4 \mathrm{~d}$ & $2,6 \mathrm{a}$ & $4,9 \mathrm{c}$ & $14,6 \mathrm{~b}$ & $11,4 \mathrm{~b}$ \\
\hline BIESEK & I & S & $1,2 \mathrm{~h}$ & $4,7 \mathrm{~b}$ & $4,1 \mathrm{a}$ & $65 \mathrm{j}$ & $14,5 \mathrm{f}$ & $2,5 \mathrm{a}$ & $3,2 \mathrm{c}$ & $11,1 \mathrm{c}$ & $6,6 \mathrm{c}$ \\
\hline ICAT 012 & I & I & 17,7 e & $6,1 \mathrm{~b}$ & $4,5 \mathrm{a}$ & $85 \mathrm{~d}$ & $20,0 \mathrm{~d}$ & $3,2 \mathrm{a}$ & $5,8 \mathrm{c}$ & $13,9 \mathrm{c}$ & $8,9 \mathrm{c}$ \\
\hline SONORA 64 & I & S & $1,1 \mathrm{~h}$ & $6,7 \mathrm{~b}$ & 5,5 a & $85 \mathrm{~d}$ & $16,3 \mathrm{e}$ & $2,8 \mathrm{a}$ & $4,5 \mathrm{c}$ & $13,0 \mathrm{c}$ & $7,7 \mathrm{c}$ \\
\hline ICAT 01338 & II & $\mathrm{T}$ & 37,3 a & 8,2 a & $5,1 \mathrm{a}$ & $79 \mathrm{f}$ & $16,2 \mathrm{e}$ & $2,6 \mathrm{a}$ & $4,0 \mathrm{C}$ & $12,4 \mathrm{c}$ & $8,3 \mathrm{c}$ \\
\hline ICAT 011 & II & $\mathrm{T}$ & 36,5 a & 8,0 a & 4,5 a & 82 e & $18,3 \mathrm{~d}$ & $2,8 \mathrm{a}$ & $5,4 \mathrm{c}$ & 13,2 c & $10,6 \mathrm{~b}$ \\
\hline ICA 2 & II & $\mathrm{T}$ & $32,7 \mathrm{~b}$ & 8,5 a & 4,5 a & $115 \mathrm{~b}$ & $21,4 \mathrm{c}$ & $3,1 \mathrm{a}$ & $5,4 \mathrm{c}$ & $16,1 \mathrm{a}$ & $9,6 \mathrm{~b}$ \\
\hline ICA 5 & II & $\mathrm{T}$ & $32,0 \mathrm{~b}$ & $6,8 \mathrm{~b}$ & 4,4 a & $85 \mathrm{~d}$ & $17,9 \mathrm{~d}$ & $2,6 \mathrm{a}$ & $4,7 \mathrm{c}$ & $12,4 \mathrm{c}$ & $6,8 \mathrm{c}$ \\
\hline CD 106 & II & $\mathrm{T}$ & $28,3 \mathrm{c}$ & 7,5 a & $5,3 \mathrm{a}$ & 81 e & $19,0 \mathrm{~d}$ & $2,5 \mathrm{a}$ & $4,7 \mathrm{c}$ & $14,4 \mathrm{~b}$ & $8,3 \mathrm{c}$ \\
\hline BRS 220 & II & $\mathrm{T}$ & $27,3 \mathrm{c}$ & 8,7 a & $4,3 \mathrm{a}$ & $84 \mathrm{~d}$ & $18,0 \mathrm{~d}$ & $2,4 \mathrm{a}$ & $4,5 \mathrm{c}$ & $12,9 \mathrm{c}$ & $10,0 \mathrm{~b}$ \\
\hline CEP 24 & III & I & $16,7 \mathrm{f}$ & $5,4 \mathrm{~b}$ & $5,5 \mathrm{a}$ & $125 \mathrm{a}$ & $25,4 \mathrm{a}$ & $3,7 \mathrm{a}$ & 8,3 a & 17,3 a & $13,9 \mathrm{a}$ \\
\hline Média & & & 13,29 & 6,76 & 5,02 & 84,61 & 18,88 & 2,8 & 5,30 & 13,57 & 9,20 \\
\hline
\end{tabular}

* Médias seguidas de mesma letra na coluna não diferem significativamente pelo teste $\mathrm{F}$ a $5 \%$ de probabilidade de erro. RCR: retomada do crescimento da raiz. CR: comprimento de raízes. NR: número de raízes por plântula. EPC: estatura de planta em campo. EPH: estatura de plântula hidropônica. CC: crescimento do coleóptilo. IPF: altura de inserção da primeira folha. CPF: comprimento da $1{ }^{a}$ folha e CSF: comprimento da 2. ${ }^{a}$ folha. Classificação ao alumínio tóxico. T: tolerantes. I: intermediário e S: sensível. 
Devido ao fato de as duas primeiras variáveis canônicas (Tabela 5) terem explicado mais de $80 \%$ da variância total de caracteres analisados $(85,5 \%$ da variância total acumulada), é possível explicar de maneira satisfatória a variabilidade manifestada entre os genótipos considerados na avaliação, permitindo interpretar o fenômeno com considerável simplificação podendo assim, representá-las em gráfico de dispersão bidirecional (Figura 2; CRUz e RegazZI, 1997).

Os resultados evidenciaram elevada associação entre os grupos formados pelas três técnicas de agrupamento empregadas, uma vez que: a) o genótipo CEP 24 que constitui o grupo III da técnica de Tocher é o mesmo do grupo IV da técnica de agrupamento da distância média e grupo IV da técnica de variáveis canônicas; b) os genótipos do grupo II de Tocher, III da distância média e III das variáveis canônicas são os mesmos, e correspondem à classificação de genótipos tolerantes ao alumínio; c) genótipos do grupo I do agrupamento de Tocher classificados como de tolerância intermediária ao alumínio também são enquadrados nos mesmos agrupamentos pela técnica da distância média e variáveis canônicas, ou seja, grupo I e II, respectivamente; d) genótipos sensíveis ao alumínio do grupo I de Tocher foram reunidos no agrupamento II pela técnica da distância média e I das variáveis canônicas (Tabela 1; Figuras 1 e 2). Essa concordância entre as técnicas de agrupamento contribuiu para a validação das inferências realizadas, sendo possível afirmar que a utilização da análise de comparação de médias, juntamente com as técnicas de agrupamento e dispersão gráfica pelas variáveis canônicas, foram eficientes na identificação de genótipos promissores para o caráter tolerância ao alumínio. Com o emprego desses genótipos em cruzamentos, há grande possibilidade de obter populações segregantes superiores para o caráter, sendo uma informação muito útil aos programas de melhoramento de trigo.

Tabela 4. Contribuição relativa das variáveis avaliadas para a dissimilaridade apresentada entre os genótipos submetidos a 10 ppm de $\mathrm{AL}^{3+}$, baseada na estatística de SINGH (1981), FAEM/UFPEL, 2004

\begin{tabular}{lccc}
\hline \multirow{2}{*}{ Variáveis } & \multicolumn{3}{c}{ Dissimilaridade genética } \\
\cline { 2 - 4 } & Autovalores & $\%$ & $\%$ acumulada \\
\hline Retomada do crescimento da raiz & $38.586,01$ & 61,18 & 61,18 \\
Estatura de plântula em hidroponia & $8.405,67$ & 13,33 & 74,51 \\
Estatura de planta a campo & $7.888,93$ & 12,51 & 87,02 \\
Comprimento da segundo folha & $2.102,37$ & 3,33 & 90,35 \\
Inserção da primeira folha & $2.079,54$ & 3,30 & 93,65 \\
Comprimento do coleóptilo & $2.037,81$ & 3,23 & 96,88 \\
Comprimento da primeira folha & $1.379,46$ & 2,19 & 99,07 \\
Número de raízes & 480,39 & 0,76 & 99,87 \\
Crescimento das raízes & 111,13 & 0,18 & 100,0 \\
\hline
\end{tabular}

Tabela 5. Variância (autovalores), variâncias percentuais e variâncias acumuladas das variáveis canônicas, visando estimar a dissimilaridade entre 23 genótipos de trigo, FAEM/UFPEL, 2004

\begin{tabular}{lccc}
\hline $\begin{array}{l}\text { Variáveis } \\
\text { Canônicas }\end{array}$ & $\begin{array}{c}\text { Variâncias } \\
\text { (autovalores) }\end{array}$ & $\begin{array}{c}\text { Variâncias } \\
\text { Percentuais }\end{array}$ & $\begin{array}{c}\text { Variâncias } \\
\text { Acumuladas }\end{array}$ \\
\hline 1 & & & $\%$ \\
2 & 74,6 & 59,9 & 59,9 \\
3 & 31,8 & 25,6 & 85,5 \\
4 & 6,7 & 5,4 & 90,9 \\
5 & 4,2 & 3,4 & 94,4 \\
6 & 2,7 & 2,2 & 96,6 \\
7 & 1,5 & 1,2 & 97,8 \\
8 & 1,3 & 1,1 & 98,9 \\
9 & 0,8 & 0,7 & 99,6 \\
\hline
\end{tabular}




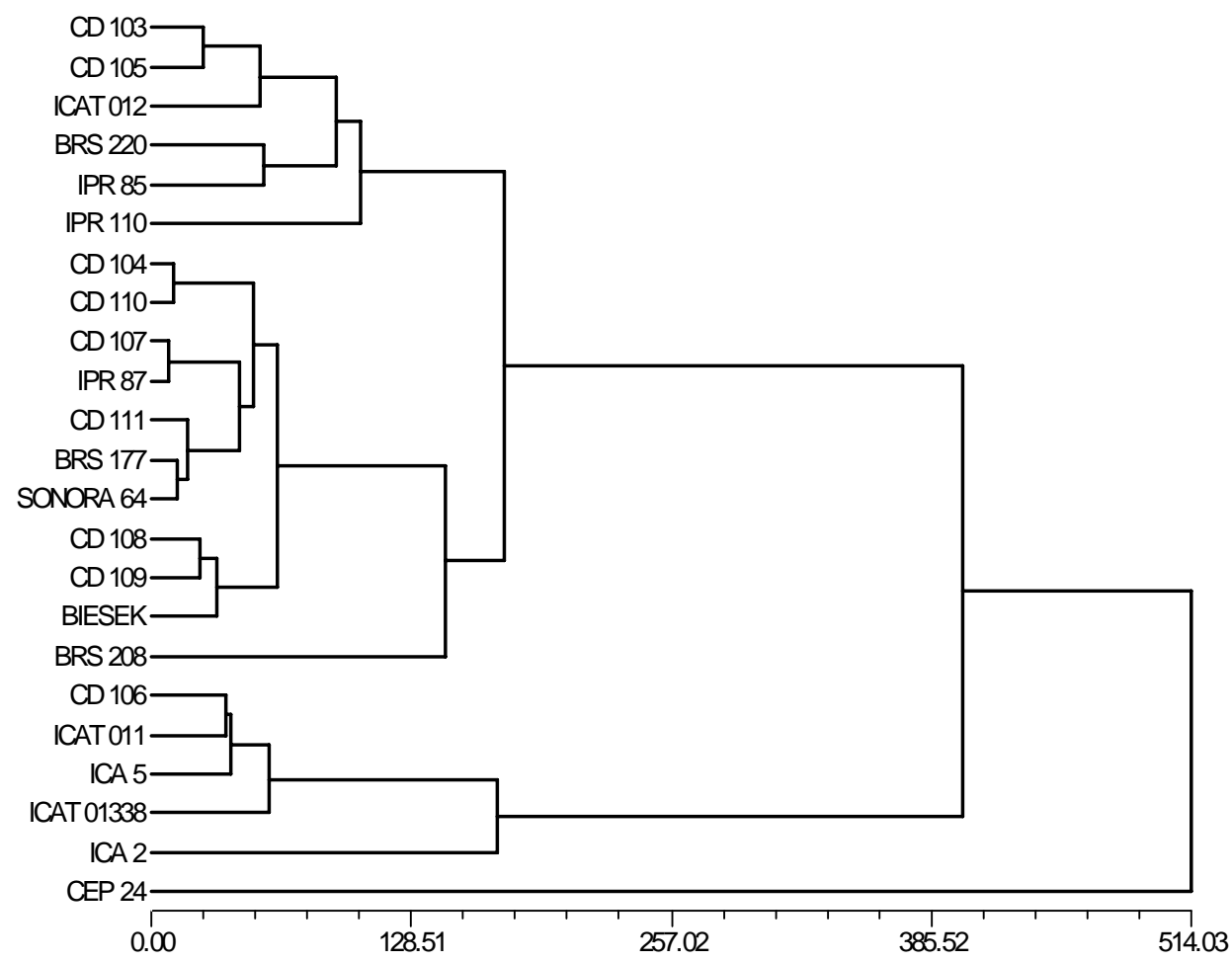

Figura 1. Dendrograma representativo da dissimilaridade genética entre 23 genótipos de trigos para variáveis avaliadas sob estresse por alumínio tóxico na concentração de $10 \mathrm{ppm}$ de $\mathrm{Al}^{3+}$ mais a estatura de planta a campo, resultante da análise de conglomeração obtidos pelo método da distância média entre genótipos, utilizando Mahalanobis como medidas de dissimilaridade. O coeficiente de correlação cofenética (r) foi de 0,81, FAEM/UFPEL, 2004.

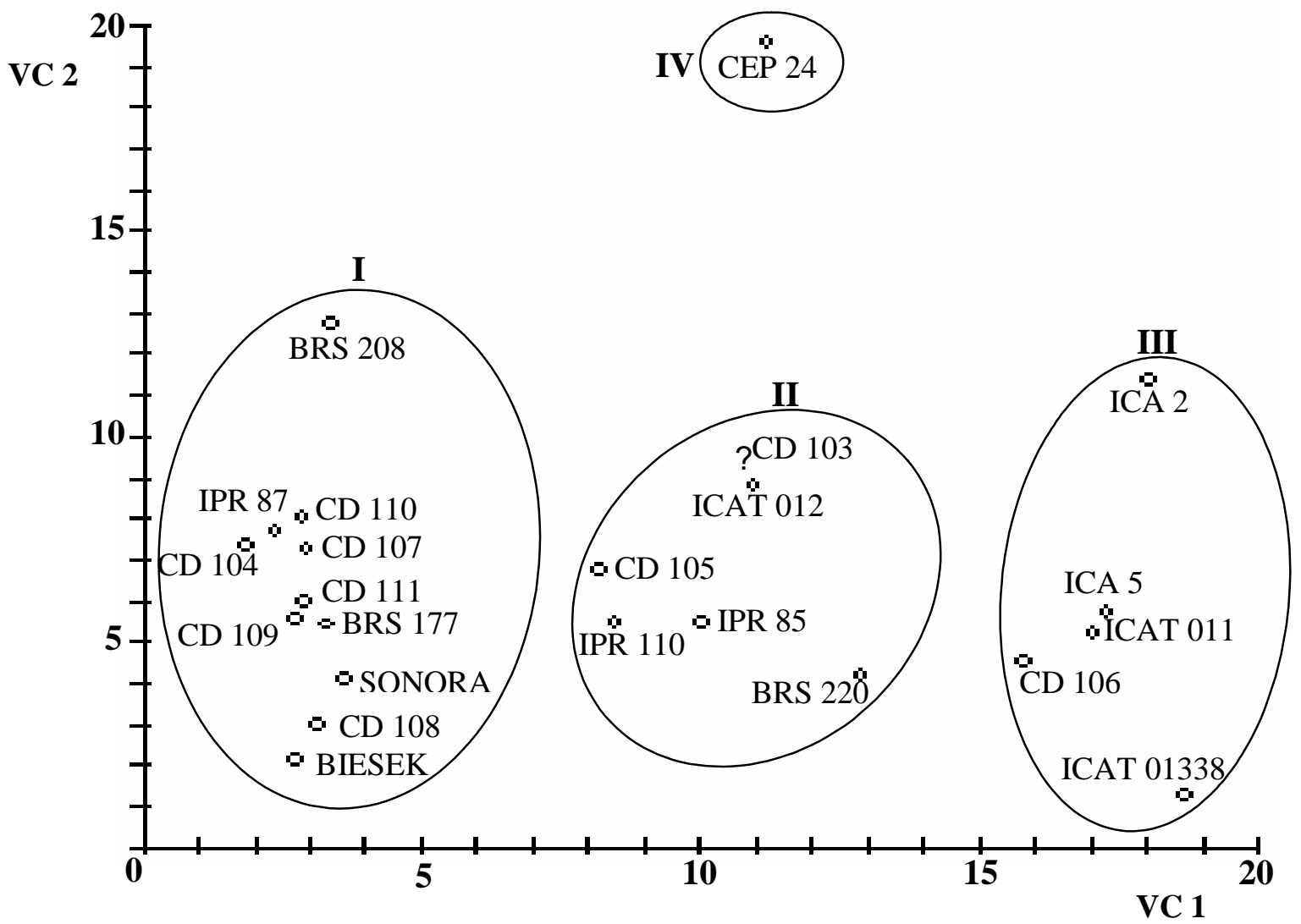

Figura 2. Dispersão gráfica dos escores da primeira (VC 1) e da segunda (VC 2) variável canônica e classificação dos genótipos em quatro grupos. FAEM/UFPEL, 2004. 


\section{CONCLUSÕES}

1. Existe variabilidade para tolerância ao alumínio entre os genótipos de trigo.

2. A variável retomada do crescimento de raiz é a que mais contribui para a dissimilaridade total entre os 23 genótipos avaliados.

3. Os genótipos ICAT 01338, ICAT 011, ICA 2, ICA 5, CD 106, CEP 24, CD 103, CD 105, IPR 85, IPR 110 e ICAT 012 são promissores para cruzamentos e obtenção de progênies superiores para tolerância ao alumínio.

\section{AGRADECIMENTOS}

Os autores agradecem à FAPERGS, ao CNPq e à CAPES pelos auxílios recebidos e bolsas de pósgraduação e produtividade em pesquisa.

\section{REFERÊNCIAS}

ANDRADE, J. M. V. Identificação e seleção em casa de vegetação, de genótipos de trigo (Triticum aestivum L.) tolerantes ao alumínio e ao manganês com modificações das características químicas do solo. 1976. 100 f. Dissertação (Mestrado em Agronomia) - Universidade Federal do Rio Grande do Sul - UFRGS, Porto Alegre.

ANIOL, A. Genetics of tolerance to aluminum in Wheat (Triticum aestioum L.) Plant and Soil, Wageningen, v.123, n. 2, p. 223-227, 1990.

BECKMANN, I. Sobre o cultivo e melhoramento do trigo (Triticum vulgare Vill) no sul do Brasil. Agronomia Sulriograndense, Porto Alegre, v. 1, n. 1/4, p. 64-72. 1954.

BENIN, G.; CARVALHO, F.I.F. DE; OLIVEIRA, A. C. et al. Uma proposta de seleção para caracteres quantitativos e qualitativos em aveia. Ciência Rural, Santa Maria, v. 34, n. 4, 2004.

CAMARGO, C.E.O.; OLIVEIRA, O. F. Tolerância de cultivares de trigo a diferentes níveis de alumínio em solução nutritiva e no solo. Bragantia, Campinas, v. 40, p. 21-23, 1981.

CAMARGO, C.E.O.; FERREIRA FILHO, A.W.P.; ROCHA JUNIOR, L.S. Melhoramento de trigo XXVII. Estimativas de variância, herdabilidade e correlações em populações híbridas, para a produção de grãos, tolerância à toxicidade do alumínio e altura de plantas. Bragantia, Campinas, v. 51, n.1, p. 21-30, 1992.

CRUZ, C.D. Programa genes: aplicativo computacional em genética e estatística. Viçosa: UFV, 2001. 648 p.

CRUZ, C.D.; REGAZZI, A.J. Modelos biométricos aplicados ao melhoramento genético. 2. ed, Viçosa: Editora UFV, 1997. 390 p.
DORNELLES, C.A.L. O uso da cultura de tecidos na geração de variabilidade para tolerância à toxicidade do alumínio e sensibilidade ao ácido giberélico em trigo (Triticum aestivum L.). 1994, 102 f. Tese (Doutorado em Agronomia Fitotecnia) - Universidade Federal do Rio Grande do Sul UFRGS, Porto Alegre.

DORNELLES, A.L.C.; CARVALHO, F.I.F.; FEDERIZZI, L.C. et. al. Avaliação simultânea para tolerância ao alumínio e sensibilidade ao ácido giberélico em trigo hexaplóide. Pesquisa Agropecuária Brasileira, Brasília, v. 32, n. 9, p. 893896, 1997.

FURLANI, P.R.; CLARK, R.B. Screening sorghum for aluminium tolerance in nutrient solution. Agronomy Journal, Madison, v. 73, n. 4, p. 587-594, 1981.

MINELLA, E.; SORRELLS, M.E. Aluminium tolerance in barley: genetic relationships among genotypes of diverse origin. Crop Science, Madison, v. 32 p. 593-598, 1992.

MOURA, W.M.; CASALI, V.W.D.; CRUZ, C.D. et al. Divergência genética em linhagens de pimentão em relação a eficiência nutricional de fósforo. Pesquisa Agropecuária Brasileira, Brasília, v.34, n.2, p.217-224, 1999.

OLIVEIRA, E.L.; PARRA, M.S. Resposta do feijoeiro a relações variáveis entre cálcio e magnésio na capacidade de troca de cátions de latossolos. Revista Brasileira de Ciências do Solo, Viçosa, v. 27, p. 859-866, 2003.

RAO, R.C. Advanced statistical methods in biometric research. New York: John Wiley, 1952. 390 p.

RIEDE, C.R.; ANDERSON, J. A. Linkage of RFLP markers to an aluminum tolerance gene in wheat. Crop Science, Madison, v. 36, p. 905-909, 1996.

ROHLF, F.J. NTSYS-pc: numerical taxonomy and multivariate analysis system, version 2.1. New York: Exeter Software, 2000. 38p.

SCOTT, A.J.; KNOTT, M.A. Cluster Analysis methods for grouping means in the analysis of variance. Biometrics, Washington, v. 30 p. 507-512, 1974.

SILVA, J.A.G.; CARVALHO, F.I.F.; OLIVEIRA, A.C. et al. Trigos di-haplóides com potencial para tolerância a toxicidade ao alumínio e a sensibilidade ao ácido giberélico em cultivo hidropônico. Revista Brasileira de Agrociência, Pelotas, v. 10, n. 1, p. 37-41, 2004.

SILVA, J.B.C.; NOVAIS, R.F.; SEDIYAMA, C.S. Comportamento de genótipos de soja em solo com alta saturação de alumínio. Pesquisa Agropecuária Brasileira, Brasília, v. 19, n. 3, p. 287298, 1984.

SINGH, D. The relative importance of characters affecting genetic divergence. The Indian Journal of Genetics \& Plant Breeding, NewDelhi, v. 41, n. 2, p. 237-245, 1981.

SOKAL, R.R.; ROHLF, F.J. The comparison of dendrograms by objective methods. Taxonomy, Berlin, v. 11, p. 33-40, 1962. 